\title{
Revelation and Reflection on Mankind by Modern Physics-Part I
}

\author{
Samo Liu \\ University Science and Technology Beijing, Beijing, China \\ Email: samo945@126.com
}

How to cite this paper: Liu, S. M. (2017). Revelation and Reflection on Mankind by Modern Physics-Part I. Open Journal of Philosophy, 7, 435-447.

https://doi.org/10.4236/ojpp.2017.74023

Received: July 27, 2017

Accepted: September 11, 2017

Published: September 18, 2017

Copyright $\odot 2017$ by author and Scientific Research Publishing Inc. This work is licensed under the Creative Commons Attribution International License (CC BY 4.0).

http://creativecommons.org/licenses/by/4.0/

\begin{abstract}
Confronted to unlimited three-dimensional spaces and possible higher-dimensional spaces, a hypothetical thinking is proposed in this paper by applying the basic form of dialectics, through physics, theology and many other field of studies, to advocate mankind to abandon internal conflicts in order to form a united planetary civilization.
\end{abstract}

\section{Keywords}

Humanity, Ideological Wisdom, Interstellar Civilization, Cosmic Resources, East-Western Culture, Religious Practice

\section{Revelation and Reflection on a Cosmic Perspective}

\subsection{Reflection and Hypothesis on Mankind Existence and Destiny}

2500 years ago, China entered the period of Spring and Autumn and the Warring States (Munro, 1969). During that period, in the ancient Eastern land, great philosophers and thinkers such as Siddhārtha, Lao Tzu, Confucius and Mo Tzu were born. They opened and created different schools of ideologies, that includes Buddhism of Siddhārtha, Taoism of Lao Tzu, Confucianism of Confucius and Mohism of Mo Tzu.

Meanwhile, western world witnessed the rise of prominent ideologists such as Socrates, Plato and Aristotle. Later, religious thinking such as Christianism and Islamism or other ideology such as Marxism emerged one after the other throughout the history.

Under the influence of oriental and occidental culture and ideologies, civilizations strive for survival and development until present, passing through periods of turmoil and unrest. Mankind has been exploiting and battling each other for survival, as well as for equality and freedom, with limited resource the planet of- 
fers.

While guiding its parent culture for survival and progress, different ideology, in order to prove its validity, has been confronting and fighting between each other ceaselessly throughout the history of mankind (Frankl, 1984).

Developments in modern science gave mankind a deep knowledge of the visible space and other fearsome technology such as the ultimate weapon of self-destruction. On one hand, they brought mankind into the internet age while on the other hand, instant self-destruction is made possible with progress in nuclear physics (Reese, 1999). With factors such as political sides, wealth division and many others, societies stay constantly in a stalemate position where a new period of global warring states has discretely begun.

Modern science proved that no substance is eternal (Erasmus, 1521). With the constant looming threat from deeper space, what is the future for the mankind and for planet Earth: to keep the present political stalemate that ultimately leads to mankind's self-destruction; to disappear in the eventual end of the planet, or to co-exist peacefully and works together for survival?

Following hypotheses on the destiny of mankind and Earth are proposed:

1) About Earth

- As a miniscule particle in the universe, under the law of cosmic motion, Earth is faced with existential threats at any time.

- Mankind uses its wisdom to create the ability to destroy all life on earth.

2) About mankind

- Flourishes and perishes along time following the path of nature.

- Mankind uses its wisdom to develop the ability which may cause the humankind self-destruct within its internal conflicts. Mankind is now fully capable of causing its own destruction if any conflict arises between nuclear possessing countries that can possibly escalade into a full-scale third world war.

- Modern physics gave mankind the ability to protect its homeland within three-dimensional spacetime, as well as the power to destroy it. Science discovered the laws of space motion and realized the threats imposed on Earth from deeper space and the probability of destroying it. Human race will disappear alongside Earth if such an apocalyptic event occurs.

- Earth civilizations would possibly be destroyed by intelligent extraterrestrial lifeform.

- Mankind makes fully use of the achievements of modern physics to research on known universe and possible extraterrestrial lifeform. Under the quasi-unlimited space resources theory, mankind should abandons its internal conflict centering on limited planetary resources to concentrate wisdom of the whole human race on exploitation of cosmic resources. Adapting unified doctrines from different religions and similarities within East-Western culture, mankind should abandons religious and cultural conflicts to adopt a singular ideology and culture representative of the human race as a civilization beyond Earth. The thinking of how can human race becomes an interstellar civilization is the key point for the continuous existence of mankind af- 
ter its transition from a planetary race to an interstellar race. Mankind should use its wisdom to exist as a glorious long lasting interstellar race.

\subsection{Revelations and Reflections Brought by Modern Physics}

In the past 2500 years, generations of great scientists proposed, researched and discovered laws of nature for the survival and progress of mankind. Technologies leaped greatly thanks to their great wisdom. Newtonian physicists opened the door to classic physics by defining laws of the visible three-dimensional space. This became the foundation for industrial revolution and great technological advancements that followed. Post-Newtonian physicist after the turn of the 20th century shaped and perfected macro and microphysics. Einstein's theory of relativity, Plank's works on quantum mechanics, Lemaitre's theory on the expansion of the universe or Hawking's theory on the black hole are amongst the most influential theories in the post-Newtonian age (Whitehead, 1913). Mankind's knowledge on macrocosm and microparticle came breakthrough in classical physics and entered an unprecedented state with decades of Hubble Space Telescope's cosmic observations. Mainstream ideology in modern physics entered the field of infinite three-dimensional and higher-dimensional spacetime. Modern science has reached a new golden era, and seeking towards the philosophy meditation of new directions.

Researches and discoveries in modern physics revealed:

1st revelation: Einstein's theory of relativity

Einstein's theory of relativity adds the notion of time onto the three-dimensional space of classical physics. This brings mankind's vision to four and higher-dimension space-time (Straumann, 1984). The theory of "speed of light remains constant at any reference point" brings the research into hyper light velocity and how is space-time affected by it.

2nd revelation: quantum mechanics

The concept of wave-particle duality in quantum mechanics expresses that when a particle is infinitely small, in the quantum concept, it can be expressed with both properties of wave and particle (Weinberg, 1972). This rises the questions:

How to physically describe a wave?

Is a particle infinitely divisible? If so, which particle is infinitely divisible and which particle can be expressed as wave when it is infinitely small?

Entanglement phenomenon for particles in quantum state is leading in spatial teleportation, how can its physical state be described?

3rd revelation: theory of the universe expansion (the Big Bang theory)

The Big Bang started theoretically as a singularity 13.7 billion years ago (Einstein, 1923). What were physical conditions at and preceding the singularity?

4 th revelation: observations of Hubble Space Telescope

Hubble Space Telescope discovered that in the vast cosmic space, there exists many similar universe. The universe that mankind lies is possibility not a unique universe. Universe is infinitely large, all materials lay in this three-dimensional 
space. Is this space consistent with the Kong, or emptiness, as described in Eastern religion?

5th revelation: theory of the black hole

The great scientist professor Hawking brought mankind into a greater field of thinking: What is the end of a black hole? What is the physical state of a black hole beyond the event horizon and what is its physical state after its demise? When the gravity of a matter is infinitely large, or when its temperature reaches infinitely high, how can that physical state be described?

For matter in three-dimensional physical space, when one or many of its physical parameters reach an extreme limit, what are their conditions? In accordance with the law of conservation of energy, would it transforms into an energy that exist in a higher-dimensional spacetime or another parallel-dimensional space?

In higher-dimensional or parallel-dimensional space, when a matter reaches a certain extreme physical state, would it downgrades back into a matter that exists in the three-dimensional space?

This triggers the following thinking:

1) What is Kong, or emptiness?

2) What is the universe?

3) With knowledge of the universe, what direction should Earth takes?

4) With knowledge of the universe, what is humanity? What is god? What defines an alien intelligent civilization?

5) At the present stage of modern physics development, what direction should it takes? What kind of revelations and reflections would it conveys to religious scholar and philosophers?

6) What direction should mankind takes facing Earth in its present stage and threat imposed on Earth by natural cosmic movements? What solutions can humanity finds?

\subsection{Continuation from the Thinking}

On the religious and cultural aspects, great religious founders and philosophers created respective great schools of thinking, religions and doctrines by applying their wisdoms and realization of the ultimate truth. Since thousands of years, their thinking has guided mankind in their struggles for survival, development and progress throughout the harsh nature.

Religious scholars reached an almost unanimous ultimate goal in term guiding the spiritual and cultural thinking of their believers. They had wished for a mankind filled with mutual love, kindness and justice, to follow methods shown by great schools of thinking, to be able to put down conflicts, to achieve equality or great unity as proposed by Chinese Confucianism.

In a cosmic perspective, Western religions discuss the existence of "god", however, this thinking has not reached a unanimous approval amongst Western philosophers (Seow, 1997). 
Eastern religious were firstly atheist, but has proposed the existence of almighty god along the lineage of religion and factions. Eastern scholars have their own opinions about the existence of god (Bartsch, 1953). Discoveries made by modern physics has seemingly been proving hypothesis and truths surrounding the universe summarized by Eastern religious believes made more than 2000 years ago. Scholars has since perceived great concepts included by ancient China's classical books such as Lianshan, or "Changes of Xia", Guizang, or "Return to the Hidden", I Ching, or "Classics of Changes", Huangdi Neijing, or "Inner Canon of the Yellow Emperor" or Dao de Jing. Thoughts and theories proposed by Confucius, Lao Tzu or Siddhārtha are being proved one by one by modern science (Cicovacki, 2009). However, a lot more are waiting to be proved.

A harsh truth from modern science pointed that the possibility of human race faces threat from deeper space highly exists (Henry, 2003). From this perspective, mankind should put greater importance ideologically, especially among prominent politicians, scholars, religious leaders, philosophers and scientists.

Todays' world faces severe challenges. It is time for mankind to reflect over these issues, from perspectives of technology, ideology and culture.

\section{Revelation and Reflection on Mankind and Intelligent Civilizations}

\subsection{Reflections on Mankind and Intelligent Civilizations}

If mankind and its civilization did not exist, the universe would still functions with corresponding governing laws, at least in observable the space. All parts of wisdom such as thoughts, cultures and languages arise from human race and its civilizations. These domains shaped mankind and became a lineage of human race. This advanced thinking and sensory system that shaped human race became a splendid trait of this universe.

Human race utilized their sophisticated thinking and thoughts to invent languages and characters throughout history of mankind. While guiding human perception of the universe, religious and philosophical wisdom that has been passed through ages has also created god, an almighty being that puzzled great minds for millennia. For a long time, religion has guided human progress in both science and thoughts and has shaped human society. The downfall is that because of the sectarian nature of religion, it brought countless conflicts and wars throughout human history.

Human race used their intelligence to advance science in order to discover and to comprehend natural laws of the universe and applied it to push the progress and advancement of the civilization. The technological achievements to date reached a peak on three-dimensional space and its corresponding natural laws. While guiding human race on reflections and explorations over four-dimensional, multi-dimensional space-time (Stewart \& Levy, 1960) and unlimited three-dimensional space, our present achievements has triggered the following thoughts: 
1) What truly is mankind civilizations, does God exist?

2) What is the state of the universe without an intelligent civilization such as human?

3) What is the difference between an intelligent lifeform and normal lifeform?

4) What is the form of other interstellar intelligent civilization, if there is any? Under what environment do they live?

5) Does alien lifeform exist?

6) Does science understand everything about three-dimensional cosmic space?

7) Is intelligence lifeform something unique to three-dimensional space only?

8) Science opened the door to the fourth dimension (three dimension space with time being the forth), what can this notion inspires the perception of intelligent life?

\subsection{Exploratory Reflections}

Eastern and western cultures, more specifically in the spiritual level, has shown a high degree of coherence for more than 2500 years. This coherence can be traced back to the Eastern legend and Western mythology in the ancient time. For example, developments and algorithms of computer was inspired by Chinese I Ching (Benedict, 1961). The modern scientific theory that all matter originates from a singularity, coincides mysteriously with the notion that all originates from "emptiness", or Kong, a term that was proposed by Eastern philosophers.

Mankind, like other possible extraterrestrial intelligent life, exists within the three-dimensional space. It is possible that other exists in a multi-dimensional space-time within the universe. When intelligent species combine with other three-dimensional matters (including organisms) under some definite and suitable circumstances, it shapes into an intelligent civilization. For example, mankind, a civilization centered on human being living on planet Earth in the three-dimensional space formed within some definite cosmic conditions.

What is god? God is a vague concept. Present day men can be viewed as godlike to men from 10,000 years ago. Men from 10,000 years later from now can also be viewed as godlike by men from today. To computers, men are godlike as we defined it. This ultimately leads to conclusion that God is a result of men's thoughts. God is a concept that men associate anything with capability way beyond present day's understanding. Without human civilizations, there will be no concept of God. Western and Eastern scholars from 2,500 years ago such as Socrates, Lao Tzu and Siddhārtha has all proposed their opinion on God (Spicker, 1970).

In Buddhism, everyone can be enlightened, everyone can become Buddha (Joy, 1956).

When talking about God and soul, some people believes in God, but cannot proves it scientifically. To others that do not believe in God, deep within themselves they lament on the diversity of destiny. With regards to soul, many believes in its existence, but others find it absurd because there is no scientific way to prove its existence to date. Vajrayana Buddhism believes that soul will un- 
dergo a journey of reincarnation and put it into practice. Unconvinced population casts doubts and uses pseudoscience to answer some popular supernatural events or "miracles". Answers to these events will require further scientific analysis, but it might requires scientist to tackle it from another perspective.

Another aspect of religious belief is expressed as superstition within some group of people. This phenomenon arises from fear that men's mind poses on unknown that future reserved for themselves. This aspect of religious belief is the least wanted by the ruling class because superstition easily brings social and mental unrests. However, social and scientific leaders have the obligation to lead and answer social phenomenon that has brought by Anicca, or impermanence, a Buddhism term that suggests that all beings in existence is subject to changes including decline and end.

Western cultures, under the guidance of ancient Greek philosophy, believe in God on one hand and instruct men to use mathematics to calculate and science to prove everything on the other hand.

So to speak, the main contribution to modern physics are made by Western Culture.

Under the guidance of Eastern religious doctrine, Eastern civilizations put greater importance on "realization by oneself" for the continuation of wisdom, e.g. by both physical experience and mental enlightenment, Because of this reason, since hundreds of years, Western scientific wisdom has surpassed that of the Eastern, but Eastern cultural and ideological wisdom has lead Western civilizations.

Great Eastern religious schools, particularly Confucianism, Taoism and Buddhism, might have discord on ideological inheritance, but on the core spiritual level, such as the notion of "Realization by oneself", these doctrines remained highly similar. Their methods of contact and experience with the universe and higher intelligent being remained surprisingly alike.

Buddhism proposed: twin-practice of Mahayana and Hinayana (and/or Vajrayana) (Todo, 1965).

Taoism proposed: twin-practice of Xing and Ming where Xing is shen, or the original spirit of the body; and Ming is jing and qi, the natural energies of the body and the universe (Todo, 1965).

Both religions realized that under a serene state, wisdom can arises from meditation. People discovered and proposed by experience that a complete of Buddhism Sādhanā, or practice, arises from: the practice of Mahayana after basic training in order to learn related knowledge, to familiarize with related discipline and to practice a strictly abstinent way of life to further purify body and mind. Upon examination, qualified Mahayana practitioners would be further introduced to Vajrayana, where one practices various tantric techniques. Gifted ones in Vajrayana Sādhanā might exhibit supernatural skills, or "miracles" described by commoners. In a way, God is man himself. But this comes with strict and harsh prerequisites. Some people tried to use modern science based on natural 
three-dimensional laws to demystify these "miracles" and has since came to conclusion that these "miracles" are one of a kind and non-repeatable. They also discovered that these people with supernatural power (non-magician) cannot exhibit their power under strong mental resistance. Scientists came to conclusion that these "miracles" were objective phenomenon that cannot publicly pass down throughout the population before science has the method to fully understand it. It is widely accepted that no conspirators should take advantage of these "miracles" in order to delude or to terrorize the populace. Real virtuous practitioners will tend to keep their power to themselves during their Sādhanā after experience with Sunnyatā, or the Buddhism term for Kong. These objective existence possibly surpassed laws of three-dimensional space as science had known. Deeper researches and thinking await scientists before science can find an answer to these phenomena and unveil its secrets.

Based on these unexplained "miracles" that happened around the globe and throughout history, extraterrestrial intelligent civilizations certainly exist beyond our knowledge.

Mainstream scientists believe without a doubt that alien civilizations exist as well (MWC Dictionary, 2008). From recent astrophysical discoveries, all stellar systems close to the Sun have a planetary system surrounding them. Many have planets located within the habitable zone of their parent star. Taking the immensity of the universe outside the solar system, if planet Earth can become the cradle for life and civilizations, the same process can very well happen on other planets. The probability that other intelligent species mature into alien civilizations is infinitely large.

The vast universe is underway following the principle of "existent and nonexistent" proposed by Lao Tzu. A possible picture of it in the three-dimensional space can be viewed as: within the vast multiverse, local universe condenses and collapses into black hole which converts it into energy within a multi-dimensional space. Under certain circumstance, energy from multi-dimensional space converts back to three-dimensional space and forms local universe. The cycle of creation of universe in the three-dimensional space follows this path. Complete answer to the life cycle of the universe can only be answered after scientists have extensive knowledge on four-dimensional space-time. (There can be more than way of energy conversion other than the "existent and nonexistent").

What is the dark matter?

A perfect universe and all things are created and completed naturally within an infinite three-dimensional space and an eternal stream of time. It is very difficult even for God to solve the enigma of all things in the universe.

No matter how great an interstellar intelligent life can be, no matter how technologically advanced they are, with thousands or millions of year ahead of mankind, or no matter how many countless power and miracles it possess, it can only be part of this universe.

Let us think in three-dimensional space for the moment. 
On Earth, men count time with second, hour, day, month and year. Universe count in cosmic unit and light year. For the universe, ten thousand Earth years is hardly noticeable in a cosmic perspective.

In this infinite universe, is the existence of humanity accidental? Civilizations has developed from stone-age into the highly advanced society as of today, what would it looks like in another ten thousand years?

It is easily imaginable that other interstellar intelligent civilizations have a small probability to be in the same development period compares to mankind. They might be very well experiencing the savage age, or their technological development and wisdom have reached a "godlike" state compares to mankind.

Intergalactic science fiction films such as Star Wars expressed that as soon as an intelligent life is discovered, if mankind treats it with the present planetary ideology, men can very possibly be annihilated well before it has a chance to retaliate. Nuclear arm is the strongest arm imaginable in our present three-dimensional bubble, but it is like a child's toy in an intergalactic perspective. Physicists have a long way to go in order to protect and preserve humanity in a cosmic context.

Why had the great religion founders proposed thinking such as learning, Sādhanā, fraternity, kindness and justice to men more than 2500 years ago? Can this be viewed as a warning message to men for what they had discovered and/or realized? The eternal way of survival for civilization should lies on the "weak-guard", tolerance and forgiveness. What they proposed are the real wisdom of humanity, and possibly correspond to the standard of cosmic wisdom.

Peace is a beautiful vocabulary that every countries or religions actively promotes. However, it conflicts with interests of everyone during the battle for resources. Why there cannot be some kind of united wisdom and action? It is for the long lasting good of planetary unity, as well as for the survival of mankind while facing the universe.

This is the original aim of the religious scholars, as well as concluded by revelations of modern physics.

\section{Revelation and Reflection on Mankind Spiritual Practice}

What is the core of humanity?

First of all, men is a matter, an animal, a being with highly advanced thought and wisdom. The body is a carrier of wisdom. Meridian acupoints, internal organs and brains are tools for the wisdom to properly function. This all combined creates the splendid human civilizations known today.

Wisdom are expressed in two forms: biological wisdom and wisdom of men.

Wisdom of men is what men are gifted upon birth. Religious and ideological founders possessed and promoted the wisdom of men.

However, present day men exhibits more characteristics of an animal with intelligence. The law of jungle made men far more dangerous and cruel compare to other animals. If this is allowed to continue, men will extinct themselves far 
before any interstellar or extraterrestrial threats arrive. This is not an exaggeration.

This dilemma requires great amount of thinking from politicians, philosophers, scientists, as well as the whole populace.

As an animal, the fulfilment of materials needs is the basic for present day men. All historical turmoil is first brought upon by the fulfilment of greed toward materials, then by the unequal law of jungles, or other sources such as conflict of ideology and culture.

The practice of politicians requires that they possess a greater wisdom compares to general populace. They have to be calm in order to use their wisdom to solve problems and conflicts peacefully. Humanity needs the guidance of great politicians. Theories in system science proposed that human has great submissiveness and follows blindly. Where politicians guide their people is crucial for the development of humanity.

The practice of entrepreneurs requires that they possess the ability to create wealth, most importantly, create wealth together with their employees. They are the God for the poor. Many peoples living in the boundary of hunger or others that live in extremes await for their salvation. Presently many great entrepreneurs or men-of-wealth use their great kind and merciful heart to act on saving the humanity from poor and sickness. This act is worth admiration and learning from the people.

Scientist is a group of men that deserve respect from the society. They exploit their wisdom to discover and research on the natural laws of the universe in order to progress humanity and lead them into the future of a cosmic civilization.

Religious scholars and philosophers thrive to flourish the splendid ideologies and wisdom left by their founders. The next step is to find whether there exist a possibility to give up or merge on some conflicting ideas or to unify and blend in ideologies such as learning, practicing, justice, kindness, love, mercy, Great Harmony, and equality in order guide humanity. A unified human culture should have less animalistic wisdom and more wisdom of men. To bring humanity into a great unified culture of men in order to face the universe seems to be what our ancestor desired.

\subsection{Professional Clergy and Practice}

Each religions have their professional practitioners. There might be difference amongst religions concerning methods of practice, but the core ideology to promote peace that has been passed down throughout generation remains similar.

Therefore, the ultimate goal of religious wisdom can be said to be highly similar. Founders of religions wished for a long lasting peaceful future for mankind.

On one hand, each religion has professional clergies that practice their ideologies alongside their followers and guide their thoughts and believes.

On the other hand, religions work closely with scientists for the heritage of mankind and the first contact with possible alien civilization in the future. This 
requires clergies to adopt a secular way of life. But they remain closer to the ultimate realization compares to the general populace.

After thousands years of perfecting, Eastern religions now have a complete set of efficient methods of professional religious practice.

\subsection{General Practice}

There might be behavior difference amongst Eastern and Western ways of thinking, but the goal to promote kindness, integrity and peace among men remains highly identical. Mankind bears great wisdom in tolerance and forgiveness. Since the beginning of recorded history, especially the last century, wars have buried seeds of hatred amongst people. Although these that advocated for wars were judged, the hatred buried between ethnic groups are not easily forgotten. Acts of confession and regrets by some war waging nations deserve appreciations from people, and reflections from some nations.

The origin of religious practice is to eradicate hatred.

How to utilize human wisdom to achieve this goal is a basic question for all men.

Chinese government proposed future goals for a prosperous, democratic, civilized, harmonious, free, equal, lawful, patriotic, ethical, honest and friendly society. Together with the win-win and peaceful international developments proposed by the Davos meeting, these promotions deserve reflections from mankind.

In some developed northern European countries, people lived happily and in wealth. People treat each other equally and with love (Cicovacki, 2009). General conscience of respecting laws and moral codes remains widespread within the whole society. This gives a close example of a utopian nation or the perfect communist nation proposed by Karl Marx. This can serves as the example for the practice of men.

In some wealthy countries in Europe or America, under the influence of religions and believes, laws and moral codes are generally better respected compares to poorer nations (Cicovacki, 2009). This social phenomenon is worth some reflection.

However, in some impoverished nations and regions, although living in difficult conditions, people still lives in faith in mutual love and respect, and abides by men's moral codes and wisdom,

The general practice of men and respective problems is worth some further thoughts.

\subsection{Practice of Commoners}

As part of the general populace, we can only become better through practice of faith.

To practice into a great sage needs to give up on commoner's desire and all temptations from Trailokya, a Buddhism term for "three realms". If not abided, it will only bring confusion and chaos for the three-dimensional world. 
If a commoner wants to practice, as the prerequisite, it requires some key guidance from the professional clergies.

Practice is not asceticism. God gave men and animals desires as the core for the survival and continuation of the specie. The control of desire is the purpose of religious practice and the inverse of materials desire. The more desire in materials men have, the more animalistic they become.

Maslow's hierarchy of needs portrays an objective view of the order of men's needs from low to high in sequence. This represents the transformation from an animal like basic needs into higher and more complex needs. When men enters higher level of needs, change in men's wisdom often follows (Reese, 1999).

In some way, faith is the basic of religious practice. Calm is the fountain of wisdom. In Confucianism, "quietness gives birth to wisdom" (Frankl, 1984). To train one's mind, if performed as asked by religious scholars and philosophers, better experience would be felt if done so by from the heart.

If one can learn from past experience, think with a calm heart, meditate deeply, and concentrate all attentions, the probability to succeed in the practice becomes greater.

During the process of transformation from animalistic wisdom toward wisdom of men, mankind might be able to develop its representative cosmic wisdom. The wisdom passed down through the generations of survival can then merge with the wisdom of the universe. The guidance and dissuasion to us by the founders of our cultures and civilizations can then be returned.

\section{Concluding Remarks}

As the higher intelligent specie, humankind were evolved and optimized throughout the natural development of the universe. Together with the technological progress of mankind, we should be able to gradually overcome threats such as illness, famine or even war. However, war has progressed to a point that it became a possible threat for the existence of our own civilization.

One solution is to respect science, fear universe, and apply a forgiving and opened culture to prevent problems and conflicts in the future. This harmonious culture between mankind and the universe will be the research direction for us in the next stage, in order to seek the true path of worldwide peaceful development.

\section{Acknowledgements}

The author would acknowledge Mr. Xiang Zhou for his assistance with the English text editing and modification.

\section{References}

(2008). Merriam-Webster's Collegiate Dictionary(11th ed., p. 615).

Bartsch, H. W. (1953). Kerygma and Myth by Rudolf Bultmann \& Five Critics. New York, NY: Harper Torchbooks.

Benedict, R. (1961). Patterns of Culture. Boston, MA: Houghton Mifflin. 
Cicovacki, P. (2009). Albert Schweitzer's Ethical Vision: A Sourcebook. New York, NY: Oxford University Press.

Einstein, A. (1923) The Principle of Relativity (p. 111). Dover: Dover Publications.

Erasmus, D. (1521). The Complaint of Peace: Translated from the Querela Pacis (A.D. 1521). Chicago: Open Court, 1917.

Frankl, V. E. (1984). Man's Search for Meaning: An Introduction to Logotherapy. New York, NY: Simon \& Schuster.

Henry, M. (2003). Matthew Henry's Concise Commentary on the Whole Bible. Nashville, TN: Thomas Nelson.

Joy, C. R. (1956). Albert Schweitzer: An Anthology. Boston, MA: Beacon Press.

Munro, D. J. (1969). The Concept of Man in Early China. Palo Alto, CA: Stanford University Press.

Reese, W. L. (1999). Dictionary of Philosophy and Religion (pp. 208-209).

Seow, C.-L. (1997). Ecclesiastes. The Anchor Bible, Doubleday. New Haven, CT: Yale University Publications.

Spicker, S. F. (1970). The Philosophy of the Body. Chicago, IL: Quadrangle Books.

Stewart, J. A., \& Levy, G. R. (1960). The Myths of Plato. Carbondale, IL: Southern Illinois University Press.

Straumann, N. (1984) General Relativity and Relativistic Astrophysics. Berlin: Springer-Verlag. https://doi.org/10.1007/978-3-642-84439-3

Todo, A. (1965). Etymological Dictionary of Chinese Characters (p. 592). Tokyo: Gakutosha.

Weinberg, S. (1972) Gravitation and Cosmology: Principles and Applications of the General Theory of Relativity. New York: John Wiley \& Sons Ltd.

Whitehead, A. N. (1913). Principia Mathematica. London: Cambridge University Press. 